\title{
РЕАЛИЗАЦИЯ ИННОВАЦИОННЫХ ТЕХНОЛОГИЙ ПРИ ПРОИЗВОДСТВЕ ПРОДУКТОВ ОБЩЕСТВЕННОГО ПИТАНИЯ
}

\section{A.V. Morgunova, R.S. Omarov, I.S. Korotaev}

\section{THE IMPLEMENTATION OF INNOVATIVE TECHNOLOGIES IN THE PRODUCTION OF PUBLIC CATERING ITEMS}

\begin{abstract}
Моргунова Анна Викторовна - канд. техн. наук, доц. каф. товароведения и технологии общественного питания Ставропольского института кооперации (филиала) Белгородского университета кооперации, экономики и права, г. Ставрополь.

E-mail: hrynya@mail.ru
\end{abstract}

Омаров Руслан Сафербегович - канд. техн. наук, доц. каф. технологии производства и переработки сельскохозяйственной продукции Ставропольского института кооперации (филиала) Белгородского университета кооперации, экономики и права, г. Ставрополь.

E-mail: doooctor@yandex.ru

Коротаев Илья Сергеевич - студ. 1-го курса Ставропольского института кооперации (филиала) Белгородского университета кооперации, экономики и права, г. Ставрополь.

E-mail: korot26@mail.ru

В статье приведены результаты исследований возможности реализации инновационных подходов при производстве продукции общественного питания. Недостаточно изучены новые способы и приемы приготовления пищи, что требует дальнейших исследований в данной сфрере. Наиболее перспективной для проведения научного исследования стала разработка новых технологий молекулярной кулинарии с точки зрения их безопасности. $B$ работе были реализованы органолептические, экспериментальные, аналитические, расчетные, измерительные методы исследования. На базе инновационного проекта в Ставропольском крае фрункционирует экспериментальное производство, на котором выполняются инновационные проекты по созданию фрруктовых и овощных блюд молекулярной кухни. При проведении исследований разраба-
Morgunova Anna Victorovna - Cand. Techn. Sci., Assoc. Prof., Chair of Merchandizing and Technology of Public Catering, Stavropol Institute of Cooperation (Branch), Belgorod University of Cooperation, Economy and Law, Stavropol.

E-mail: hrynya@mail.ru

Omarov Ruslan Saferbegovich - Cand. Techn. Sci., Assoc. Prof., Chair of Production Technology and Processing of Agricultural Production, Stavropol Institute of Cooperation (Branch), Belgorod University of Cooperation, Economy and Law, Stavropol.

E-mail: doooctor@yandex.ru

Korotaev Ilya Sergeyevich - 1-Year Student, Stavropol Institute of Cooperation (Branch), Belgorod University of Cooperation, Economy and Law, Stavropol.

E-mail: korot26@mail.ru

тывались блюда молекулярной кухни в виде пены, называемые эспумами. Приготовление эспум можно отнести к методу, в основе которого лежит образование пен с жидкими веществами, где есть воздух. При их изготовлении используются в основном натуральные компоненты, поэтому блюда молекулярной кухни являются сбалансированными и полезными. Обычно для введения пузырьков газа в эспумы используют специальные сифоны или кремеры. В качестве пропеллента при изготовлении эспум в пищевой индустрии в основном применяются диазомонооксид и углекислый газ. Данные газы не представляют никакой опасности для потребителей, поскольку их концентрация в готовых блюдах очень мала. Конечным результатом научного эксперимента является разработка новых низкокалорийных блюд молекулярной кулинарии с мак- 
симальным сохранением полезных свойств продуктов - закуски «Морковь на баклажане», тыквенного супа-пены и десерта «Слоеная эспума». Органолептическая оценка разработанных образцов блюд свидетельствует, что исходные ингредиенты хорошо сочетаются между собой.

Ключевые слова: молекулярная кулинария, безопасность, эспума, сифон, кремер, технология.

The results of the researches of the possibility of realization of innovative approaches at production of public catering were given in the study. New ways and methods of cooking demanding further researches in this sphere have been insufficiently studied. The development of new technologies of molecular cuisine from the point of view of their safety is the most perspective for carrying out scientific research. In the study organoleptic, experimental, analytical, calculation, measuring methods of research were realized. On the basis of innovative project in Stavropol Region experimental production on which innovative projects on creation of fruit and vegetable dishes of molecular cuisine were carried out. When carrying out the researches the dishes of molecular cuisine in the foam form called espumas were developed. The preparation of espumas could be referred to the method which cornerstone formation of foams with liquid substances having the air inside. At their production generally natural components were used therefore the dishes of molecular cuisine were balanced and useful. Usually for the introduction of vials of gas into espumas special siphons or creamer are applied. As propellant at production of espumas in food industry diazomonoxide and carbon dioxide are generally used. These gases do not constitute any danger to consumers as their concentration in ready dishes is very small. Final result of scientific experiment was the development of new lowcalorie dishes of molecular cuisine with maximum preservation of useful properties of products - appetizers "Carrot on Eggplant", pumpkin soup foam and the dessert "Puffed Espuma ". Organoleptic assessment of developed samples of dishes testified that initial ingredients went well.
Keywords: molecular cookery, safety, espuma, siphon, creamer, technology.

Введение. Современную концепцию производства продукции общественного питания нельзя представить без использования старинных и традиционных рецептов. Однако реализация новых научных подходов и технологий при разработке высококачественных продуктов питания является одним из перспективных направлений в пищевой промышленности. Появление на отечественном рынке новых видов оборудования для обработки сырья растительного и животного происхождения создает большие возможности для внедрения в общественном питании инновационных технологий. Предпосылками разработки новых рецептур и технологий с точки зрения их безопасности являются проблемы несбалансированного питания; загрязнения окружающей среды, приводящие к различным видам патологий у населения; появление новых видов продуктов, которые ранее были не доступны; ужесточение современных стандартов обслуживания [1]. Большое значение для профилактики заболеваний имеет нутриентно-сбалансированное питание. Современные технологии позволяют изготавливать продукты с заданными лечебными или профилактическими свойствами, которые помогают сгладить урон от внешних фракторов окружающей среды [2].

В сети общественного питания России широко представлен ассортимент фастфуда, разработанного непосредственно заинтересованными производителями. Использование сырья животного происхождения, пищевых добавок и жиров приводит к улучшению органолептических характеристик готового продукта, однако снижает их безопасность и пищевую ценность. Стратегия повышения качества пищевых продуктов ориентирует многих производителей к производству полуфабрикатов и готовых блюд нового поколения, сбалансированных по аминокислотному, минеральному составу, в которых снижено содержание соли, сахара, насыщенных жирных кислот.

Изучив особенности организации производственных процессов предприятий общественно- 
го питания, можно сделать вывод, что большинство из них функционируют при условии обеспечения гигиены, полного санитарного режима, контроля качества приготавливаемых блюд. Однако новые направления в кулинарии, недавно появившиеся в российском ресторанном бизнесе, такие как молекулярная кулинария, sous-vide, фуддпейринг, термомиксинг, кулинарный визаж, недостаточно изучены и требуют дальнейших исследований. Сегодня одним из наиболее перспективных для научных исследований способов приготовления еды стала молекулярная кухня. В молекулярной кулинарии, в отличие от блюд и продуктов достижений химической промышленности, используют в основном лишь натуральные компоненты, поэтому блюда молекулярной кухни являются сбалансированными и полезными.

Добавки, используемые для приготовления молекулярной пищи, являются естественными химическими соединениями. В технике молекулярной кулинарии используются такие стабилизаторы и добавки, как альгинат натрия, хлорид кальция, лецитин, жидкий азот и другие. Упомянутый выше альгинат натрия является абсолютно натуральным и безвредным для здоровья человека веществом, которое получают из водорослей ламинарии. Хлорид кальция относится к разряду естественных эмульгаторов и одновременно является лекарственным веществом, восполняющим нехватку этой соли в организме. Хлорид кальция выводит токсины из организма, облегчает воспалительные и аллергические реакции организма. Соевый или подсолнечный лецитин является натуральным веществом, получаемым из растительных масел. Его аналог животного происхождения в большом количестве содержится в яичных желтках. Жидкий азот, который используется для быстрого замораживания блюд и их эффектной подачи в газообразном состоянии, является основной составляющей воздуха, которым мы дышим [3]. Таким образом, во многих процессах приготовления блюд молекулярной кухни нет ничего вредного, поэтому технологии молекулярной кулинарии можно отнести к безопасным.

Цель исследования. Анализ существующих и разработка новых технологий молекулярной кулинарии с точки зрения их безопасности для получения продуктов с необычной консистенцией и вкусовыми сочетаниями.

Задачи исследования: изучение инновационных подходов в организации производственных процессов предприятий общественного питания; разработка ассортимента эспум и технологии приготовления новых блюд молекулярной кухни с максимальным сохранением полезных свойств продуктов и их безопасности при употреблении.

Объект и методы исследования. В наших исследованиях проведено научное обоснование и подбор органолептических, экспериментальных, аналитических, расчетных, измерительных методов. В работе были реализованы самые современные научно-исследовательские разработки ведущих ученых в области классического товароведения, экспертизы качества, инновационных кулинарных технологий и прикладных биотехнологий. В качестве объекта исследований использовались фруктовые и овощные блюда молекулярной кухни.

Результаты и их обсуждение. На базе инновационного проекта в Ставропольском институте кооперации функционирует экспериментальное производство, на котором выполняются творческие эксперименты сотрудников по созданию здоровых продуктов нового поколения.

Первым этапом в создании блюд молекулярной кулинарии было исследование крестьянско-фрермерских хозяйств с целью поиска свежих, качественных и натуральных продуктов питания. Объехав большое количество ферм и хозяйств, мы детально познакомились с проблематикой данного бизнеса, что подтолкнуло команду проекта внимательно относиться к контролю качества исходного сырья, ведь оно может оказывать непосредственное влияние не только на органолептические свойства различных видов продукции, но и на функциональнотехнологические.

Вторым этапом являлось конструирование продуктов питания с заданными характеристиками в соответствии с принципами безопасного питания. Проектирование рецептур блюд основывалось на использовании методов и приемов молекулярной кухни, отличающейся от традиционных технологий способами приготовления 
низкокалорийных блюд с максимальным сохранением полезных свойств продуктов [4]. В нашем исследовании разрабатывались блюда молекулярной кухни в виде пены, называемые эспумами. Приготовление эспум можно отнести к кулинарному методу, в основе которого лежит образование пен с жидкими веществами, где есть воздух. При использовании твердых продуктов их необходимо максимально измельчить или разжижать. Метод производства эспум позволяет полностью или частично отказаться от сливок и яиц в качестве стабилизатора. Вследствие этого натуральный вкус и аромат основных ингредиентов ощущаются сильнее. В процессе дегустации чувствуется лишь вкус, так как такие блюда имеют неосязаемую текстуру [3].

Для введения пузырьков газа в эспумы используют специальный сифон или кремер. Использование сифона основано на насыщении продуктов пузырьками, которое способствует их взбиванию. Обычно сифоны используются для газирования напитков и сливок. Они часто встречаются в кофейнях и ресторанах. Сифоны подразделяют на зарядные и автосифоны. Кремер может не только газировать напитки, но и взбивать массы, то есть является универсальным. Преимуществом эспум, приготовленных в кремере, является более пористая структура, отлично держащая свою фрорму. Кремер изготавливается из нержавеющей стали и является настоящим профессиональным инструментом, который имеет большой функционал и надежность. Он довольно легкий, хорошо остывает в холодильнике и долго сохраняет продукт внутри холодным, но также отлично работает с горячими массами, чем не может похвастаться алюминиевый корпус, в котором продукт может начать окисляться. В качестве пропеллента при изготовлении эспум в пищевой индустрии в основном применяется диазомонооксид и углекислый газ в баллончиках. Данные газы не представляют никакой опасности для потребителей, поскольку их концентрация в готовых блюдах очень мала [3].

Для приготовления воздушной пены в виде эспумы можно использовать картофрельное, морковное, тыквенное или любое другое овощное пюре. Правильная воздушная пена обеспечивает контрастную текстуру и отлично дополняет любое блюдо. Возможно использование эспум как декора для украшения холодных и горячих десертов. Легкие, с нежной кислинкой и воздушностью пены могут добавить блюду дополнительный оттенок или вкус. Сифон может использоваться также для изготовления взбитых сливок. При этом гарантированы экономия времени и увеличение производительности до 5 раз. Закрытая система сохраняет качество и гарантирует безопасность блюда. Охлажденные компоненты можно хранить в холодильной камере в течение нескольких дней [5].

Нами разработаны технология и технологическая схема приготовления эспум. Общая технологическая схема приготовления эспум представлена на рисунке.

В ходе проведенных исследований нами разработаны экспериментальные образцы новых блюд для молекулярной кулинарии: закуска «Морковь на баклажане», тыквенный суп-пена и десерт «Слоеная эспума». Из литературных источников было установлено, что схема приготовления эспум различается лишь тем, какой стабилизатор был использован при производстве пены. В наших исследованиях в качестве стабилизатора холодной закуски применяли сыр и сливки, при изготовлении тыквенного супа-пены использовались пассированная мука и сливки, а при создании десерта готовились два вида эспум: первая была приготовлена с желатином, а вторая получена комбинацией желатина и сливок.

Органолептическая оценка разработанных образцов блюд молекулярной кухни свидетельствует, что вкус, аромат хорошо сочетаются со вкусом мясных компонентов. Балловая оценка высокая - 9,4-9,6 по 10-балльной шкале. Следующим этапом научного исследования станет исследование качественных, функциональнотехнологических, фризико-химических характеристик и микробиологических показателей образцов блюд молекулярной кухни. 


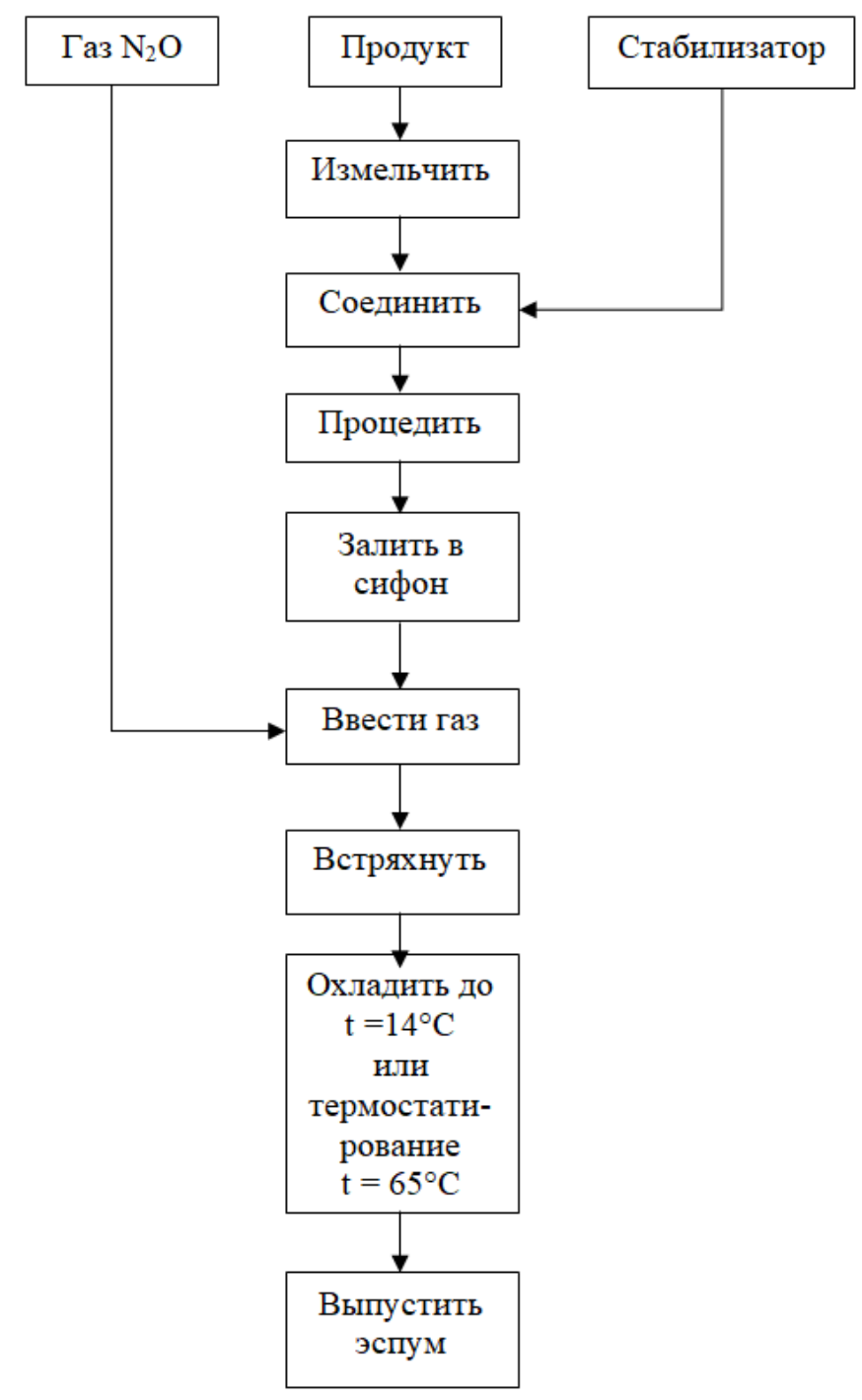

Общая технологическая схема приготовления эспум

Выводы. Проведенные исследования показали, что реализация новых научных подходов при производстве продуктов общественного питания дает новые возможности использования молекулярной кухни в данной сфере. Благодаря приемам молекулярной кухни нами разработаны ассортимент эспум и технология приготовления новых блюд. В частности, разработаны технологические схемы на производство новых блюд для молекулярной кулинарии: закуска «Морковь на баклажане», тыквенный суппена и десерт «Слоеная эспума». Инновационность разработанных нами блюд заключена в максимальном сохранении полезных свойств продуктов и их безопасности при употреблении.

Благодаря интересу и активному участию профессиональных поваров и ученых по всему миру молекулярная кулинария продолжает захватывать определенную часть рынка общественного питания за счет определенных конкурентных преимуществ.

\section{Литература}

1. Садовой В.В., Трубина И.А. Исследование молекулярных свойств желатина методами молекулярной и квантовой механики // Хранение и переработка сельхозсырья. - 2008. - № 6. - C. 20-21.

2. Моргунова А.В. Разработка технологии пищевых продуктов с профилактическими свойствами на базе компьютерного моделирования // Приоритетные и инновационные технологии в животноводстве - основа мо- 
дернизации агропромышленного комплекса России: мат-лы Междунар. науч.-практ. конф. науч. сотр. и преп. / Ставропольский государственный аграрный университет. Ставрополь, 2016. - С. 124-127.

3. Омонт Р. Молекулярная кулинария. - М.: Центрполиграф, 2015. - 176 с.

4. Исследование молекулярных структур хитозана и сукцината хитозана / В.В. Садовой, С.А. Левченко, И.А. Евдокимов [и др.] // Хранение и переработка сельхозсырья. 2010. - № 3. - C. 34-36.

5. Чернышов А.В., Моргунова А.В., Касьянов Г.И. Информационные технологии в сфере общественного питания // Мат-лы III Всерос. науч.-метод. чтений проф.-преп. состава и аспирантов Ставропольского института кооперации (филиала) БУКЭП. - Ставрополь, 2016. - С. 182-185.

\section{Literatura}

1. Sadovoj V.V., Trubina I.A. Issledovanie molekulyarnyh svojstv zhelatina metodami molekulyarnoj i kvantovoj mekhaniki //
Hranenie i pererabotka sel'hozsyr'ya. - 2008. - № 6. - S. 20-21.

2. Morgunova A.V. Razrabotka tekhnologii pishchevyh produktov $s$ profilakticheskimi svojstvami na baze komp'yuternogo modelirovaniya // Prioritetnye i innovacionnye tekhnologii $\mathrm{v}$ zhivotnovodstve - osnova modernizacii agropromyshlennogo kompleksa Rossii: mat-ly Mezhdunar. nauch.-prakt. konf. nauch. sotr. i prep. I Stavropol'skij gosudarstvennyj agrarnyj universitet. Stavropol', 2016. - S. 124-127.

3. Omont $R$. Molekulyarnaya kulinariya. - M.: Centrpoligraf, 2015. - $176 \mathrm{~s}$.

4. Issledovanie molekulyarnyh struktur hitozana i sukcinata hitozana / V.V. Sadovoj, S.A. Levchenko, I.A. Evdokimov [i dr.] // Hranenie i pererabotka sel'hozsyr'ya. - 2010. - № 3. S. 34-36.

5. Chernyshov A.V., Morgunova A.V., Kas'yanov G.I. Informacionnye tekhnologii $v$ sfere obshchestvennogo pitaniya /I Mat-ly III Vseros. nauch.-metod. chtenij prof.-prep. sostava i aspirantov Stavropol'skogo instituta kooperacii (filiala) BUKEP. - Stavropol', 2016. S. 182-185. 